\title{
THE STECHKIN INEQUALITY FOR FOURIER MULTIPLIERS ON VARIABLE LEBESGUE SPACES
}

\author{
AleXeI Yu. KARLOVICH
}

Abstract. We prove the Stechkin inequality for Fourier multipliers on variable Lebesgue spaces under some natural assumptions on variable exponents.

Mathematics subject classification (2010): 42A45, 46E30, 46B70.

Keywords and phrases: Fourier multiplier, Stechkin inequality, variable Lebesgue space, function of finite total variation, Hardy-Littlewood maximal operator.

\section{REFERENCES}

[1] A. Böttcher, Yu. I. Karlovich, And I. M. Spitkovsky, Convolution Operators and Factorization of Almost Periodic Matrix Functions, Birkhäuser, Basel, 2002.

[2] A. BötTCher AND M. SEYBold, Wackelsatz and Stechkin's inequality for discrete Muckenhoupt weights, Fakultät für Mathematik, TU Chemnitz, 99-7, Unpublished preprint is available on A. Böttcher's web page, 1999.

[3] D. CruZ-Uribe and A. Fiorenza, Variable Lebesgue Spaces, Birkhäuser, Basel, 2013.

[4] D. Cruz-Uribe, A. Fiorenza, J. M. Martell, and C. PÉrez, The boundedness of classical operators on variable $L^{p}$ spaces, Ann. Acad. Sci. Fenn., Math. 31 (1), 2006, 239-264.

[5] L. Diening, P. Harjulehto, P. HästÖ, And M. RŮŽIČKa, Lebesgue and Sobolev Spaces with Variable Exponents, Springer, Berlin, 2011.

[6] H. R. Dowson, Spectral Theory of Linear Operators, Academic Press, London, New York, San Francisco, 1978.

[7] R. Duduchava, Integral Equations with Fixed Singularities, Teubner Verlagsgesellschaft, Leipzig, 1979.

[8] I. Gohberg And N. Krupnik, Introduction to the Theory of One-Dimensional Singular Integral Equations, Shtiintsa, Kishinev, 1973 (in Russian).

[9] I. Gohberg AND N. KRUPNIK, One-Dimensional Linear Singular Integral Equations. I. Introduction, Birkhäuser, Basel, 1992.

[10] I. Gohberg And N. KRUPNiK, One-Dimensional Linear Singular Integral Equations. II. General Theory and Applications, Birkhäuser, Basel, 1992.

[11] A. YU. KARLOVICH, Maximally modulated singular integral operators and their applications to pseudodifferential operators on Banach function spaces, Contemporary Mathematics 645, in "Function Spaces in Analysis", 2015, 165-178.

[12] A. Yu. Karlovich And I. M. Spitkovsky, Pseudodifferential operators on variable Lebesgue spaces, Operator Theory: Advances and Applications 228, in: "Operator Theory, Pseudo-Differential Equations, and Mathematical Physics. The Vladimir Rabinovich Anniversary Volume”, 2013, 173183.

[13] A. Yu. Karlovich A. Yu. AND I. M. Spitkovsky, The Cauchy singular integral operator on weighted variable Lebesgue spaces, Operator Theory: Advances and Applications 236, in: "Concrete Operators, Spectral Theory, Operators in Harmonic Analysis and Approximation", 2014, 275-291.

[14] V. M. KokIlashvili And S. G. SAmKo, Singular operators and Fourier multipliers in weighted Lebesgue spaces with variable index, Vestn. St. Petersbg. Univ., Math. 41 (2), 2008, 134-144.

[15] V. M. KoKILASHVILI AND S. G. SAMKO, Operators of harmonic analysis in weighted spaces with non-standard growth, J. Math. Anal. Appl. 352 (1), 2009, 15-34. 
[16] A. K. LERnER, Some remarks on the Hardy-Littlewood maximal function on variable $L^{p}$ spaces, Math. Z. 251 (3), 2005, 509-521.

[17] I. P. NATANSON, Theory of Functions of a Real Variable, Frederick Ungar Publishing Co., New York, 1955.

[18] S. B. Stechkin, On bilinear forms, Dokl. Akad. Nauk SSSR 71 (2), 1950, 237-240 (in Russian). 